\title{
Effect of cardiopulmonary bypass and aortic clamping on functional residual capacity and ventilation distribution in children
}

Britta S. von Ungern-Sternberg, MD, ${ }^{\text {a }}$ Ferenc Petak, PhD, ${ }^{\mathrm{b}}$ Sonja Saudan, MD, Michel Pellegrini, MD, ${ }^{a}$ Thomas 0. Erb, MD, MHS, ${ }^{\mathrm{c}}$ and Walid Habre, MD, PhD, ${ }^{a}$ on behalf of the Swiss Paediatric Respiratory Research Group

Earn CME credits at http://cme.ctsnetjournals.org
From the Pediatric Anesthesia Unit, ${ }^{\text {a }}$ Geneva Children's Hospital, Geneva, Switzerland; the Department of Medical Informatics, ${ }^{\text {b }}$ University of Szeged, Szeged, Hungary; and the University Children's Hospital, ${ }^{\mathrm{c}}$ Basel, Switzerland.

The work should be attributed to the Division of Anesthesia, Geneva Children's Hospital, Geneva, Switzerland.

Supported by the Swiss National Science Foundation (SNSF 105828/1), MSD Scholarship of the Swiss Paediatric Respiratory Research Group (SPRRG), and the Departments of Anesthesia, Universities of Geneva and Basel, Switzerland. Ferenc Petak is supported by the Bolyai János research fellowship.

Received for publication Nov 28, 2006; revisions received March 28, 2007; accepted for publication March 29, 2007.

Address for reprints: Britta von UngernSternberg, MD, Pediatric Anesthesia Unit, Geneva Children's Hospital, 6, Rue Willy Donzé, CH-1205 Geneva, Switzerland (Email: britta.reglivonungern@hcuge.ch).

J Thorac Cardiovasc Surg 2007;134:1193-8

$0022-5223 / \$ 32.00$

Copyright $(9) 2007$ by The American Association for Thoracic Surgery

doi:10.1016/j.jtcvs.2007.03.061
Objective: To characterize factors that contribute to lung function impairment after cardiopulmonary bypass, we assessed functional residual capacity and ventilation homogeneity during the perioperative period in children with congenital heart disease who are to undergo surgical repair.

Methods: Functional residual capacity and lung clearance index were measured by using a sulfur hexafluoride washout technique in 24 children (aged 0-10 years). Measurements of functional residual capacity and ventilation distribution were performed after induction of anesthesia, at different stages of the surgical procedure, and up to 90 minutes after skin closure. Anesthesia was standardized, and ventilator settings, including the fraction of inspired oxygen, were kept constant throughout the study period.

Results: Sternotomy and retractor insertion led to a significant increase in functional residual capacity (mean [SD], 24\% [14\%]), followed by a similar percentage decrease in the resting volume after a significant reduction in pulmonary blood flow during cardiopulmonary bypass with aortic clamping. Although reestablishing pulmonary blood flow increased functional residual capacity (10\% [6\%]), chest closure led to a decrease in functional residual capacity of $36 \%(14 \%)$ that only slightly improved during the first 90 minutes after surgical intervention. Changes in lung clearance index were affected conversely compared with changes in functional residual capacity at all assessment times.

Conclusions: These results confirmed that chest wall condition and pulmonary circulation affect lung volumes and ventilation homogeneity. Although opening of the chest wall improved alveolar recruitment and ventilation homogeneity, blood flow appeared essential for alveolar stability, presumably by exerting a tethering force caused by the filled capillaries on the alveolar walls and therefore contributing to an increase in resting lung volume.

$\mathrm{M}$ any factors impair lung function after cardiopulmonary bypass (CPB). For example, CPB affects lung function by inducing an inflammatory response $\mathrm{e}^{1,2}$ or promoting interstitial water extravasation. ${ }^{3}$ In addition, congenital heart disease is often associated with an impaired pulmonary hemodynamic condition that has a great effect on the mechanical properties of the lung. ${ }^{4,5}$ In spite of improved perioperative ventilation strategies in children with congenital heart disease, their ventilatory pattern and performance remain impaired in the postoperative period, enhancing the ventilation-perfusion mismatch. ${ }^{6-12}$ All these phenomena lead to airway closure, atelectasis, decrease in functional residual capacity (FRC), and consecutive hypoxemia.

The tethering effect exerted by pulmonary capillary perfusion pressure on the alveolar wall is a pathophysiologic mechanism responsible for airway closure that 

Abbreviations and Acronyms
$\mathrm{CPB}=$ cardiopulmonary bypass
$\mathrm{FiO}_{2}=$ fraction of inspired oxygen
FRC $=$ functional residual capacity
LCI $=$ lung clearance index
$\mathrm{SF}_{6}=$ sulfur hexafluoride

contributes to alveolar stability and greatly affects the mechanical properties of the lung. ${ }^{13}$ Because pulmonary perfusion pressure changes profoundly during cardiac surgery with $\mathrm{CPB}$, the consequent loss in the stability of the alveolar capillary network might have a marked effect on the resting volume and therefore gas exchange. We hypothesized that FRC and ventilation distribution would be influenced by both changes in chest wall condition and the pulmonary hemodynamic condition throughout a cardiac surgical procedure with $\mathrm{CPB}$ and into the postoperative period.

\section{Materials and Methods}

After obtaining approval by our institutional ethics committee and parental written informed consent, 24 children ( 3 months-10 years of age) undergoing cardiac surgery with $\mathrm{CPB}$ were consecutively included over a 6-month period. Recruitment was performed independently of the child's cardiac pathology.

\section{Anesthesia}

All patients received $0.5 \mathrm{mg} / \mathrm{kg}$ midazolam for premedication 1 hour before anesthesia. Induction of anesthesia was achieved either by means of inhalation induction with sevoflurane (up to $5 \%$ ) or intravenous induction with propofol $(2-3 \mathrm{mg} / \mathrm{kg}$ ). In the case of inhalational induction, sevoflurane was stopped as soon as an intravenous access was achieved. Tracheal intubation with a cuffed endotracheal tube (Mircocuff; Weinheim, Germany) was facilitated by the application of atracurium $(0.5 \mathrm{mg} / \mathrm{kg})$, followed by additional boli of atracurium to ensure a complete neuromuscular blockade during the whole study period. Analgesia was provided by means of intravenous administration of a bolus of $0.5 \mu \mathrm{g} / \mathrm{kg}$ sufentanil and $0.15 \mathrm{mg} / \mathrm{kg}$ ketamine, followed by a continuous infusion of sufentanil and ketamine at doses of 0.5 to $1 \mu \mathrm{g} \cdot \mathrm{kg}^{-1}$ $\cdot \mathrm{h}^{-1}$ and $0.1 \mu \mathrm{g} \cdot \mathrm{kg}^{-1} \cdot \mathrm{h}^{-1}$, respectively. Anesthesia was maintained with 8 to $10 \mathrm{mg} \cdot \mathrm{kg}^{-1} \cdot \mathrm{h}^{-1}$ intravenous propofol, as deemed necessary by the attending pediatric anesthesiologist.

All patients received $100 \%$ oxygen until correct tracheal intubation was confirmed; then they were mechanically ventilated with a Centiva/5 critical care ventilator (Datex Ohmeda, Helsinki, Finland) at a fraction of inspired oxygen $\left(\mathrm{FIO}_{2}\right)$ of 0.5 , a tidal volume of $10 \mathrm{~mL} / \mathrm{kg}$ body weight, and a respiratory rate adapted to an end-tidal carbon dioxide value of $5 \mathrm{kPa}$. The ventilator delivered a continuous bypass flow that was needed to ensure an exact delivery of the tracer gas at all times. This bypass flow in the breathing system created a positive end-expiratory pressure of $3 \mathrm{~cm} \mathrm{H}_{2} \mathrm{O}$ in the system. During the time of aortic clamping (after the FRC measurement), all patients received continuous positive airway pressure of $6 \mathrm{~cm} \mathrm{H}_{2} \mathrm{O}$, and the $\mathrm{FIO}_{2}$ was reduced to $0.21 \%$. After aortic declamping, a lung recruitment maneuver to total lung capacity was performed by manually increasing the airway pressure to 37 to $40 \mathrm{~cm} \mathrm{H}_{2} \mathrm{O}$ of peak inspiratory pressure for 10 consecutive breaths. ${ }^{14,15}$ Then mechanical ventilation was restarted, as described above.

All children were equipped, according to our institutional standard, with a radial arterial line, as well as a central venous line. Heart rate, oxygen saturation, blood pressure, and central venous pressure were monitored continuously.

\section{Assessment Times}

In patients receiving inhalational induction of anesthesia, it was ensured that there was no further end-expiratory sevoflurane for at least 2 minutes, as measured by using the anesthetic workstation (Draeger Primus, Luebeck, Germany). Measurements of FRC and ventilation distribution were performed (1) 5 minutes after intubation, (2) after midsternotomy, (3) after insertion of the retractor, (4) after the start of CPB, (5) after aortic clamping and during the administration of the cardioplegic solution, (6) after aortic declamping but still during $\mathrm{CPB}$, (7) after weaning from $\mathrm{CPB}$ while the chest was still open and the retractor was in situ, (8) after closure of the pericardium and retractor removal, (9) 5 minutes after chest closure, and (10-12) 30, 60, and 90 minutes after the end of the operation, respectively. Three measurements were performed for each study condition, except measurement 5 (after aortic clamping), which was limited to the application time of the cardioplegia and therefore allowed for only 2 assessments. For all calculations, the average value of all assessments was used.

\section{Measurement Techniques}

An ultrasonic transit-time airflow meter (Exhalyzer D with ICU insert; Eco Medics, Duernten, Switzerland) that simultaneously measures flow and molar mass of the breathing gas in the mainstream was placed between the ventilator circuit and the endotracheal tube. The measurement setup has been previously described in detail. ${ }^{16,17}$ Briefly, a multibreath washout technique with sulfur hexafluoride $\left(\mathrm{SF}_{6}\right)$ as the tracer gas was used to measure FRC, physiologic dead space volume, and lung clearance index (LCI). LCI is commonly used to measure the degree of ventilation homogeneity. ${ }^{18-23}$ LCI is calculated as the cumulative expired volume needed to lower the end-tidal tracer gas $\left(\mathrm{SF}_{6}\right)$ concentration to one fortieth of the starting concentration divided by the FRC (ie, the number of lung volume turnovers needed to clear the lungs of the marker gas). ${ }^{24,25}$ The number of volume turnovers was calculated by using the cumulative expired alveolar volume. ${ }^{21,23}$ An increase in LCI reflects a decrease in ventilation homogeneity. FRC, dead space, and LCI calculations were performed with Spiroware software (version 1.5.2; ndd Medizintechnik AG, Zurich, Switzerland).

\section{Statistical Analysis}

Sample size calculations were performed with the nQuery Advisor 4.0 software (Statistical Solutions Ltd, Boston, Mass). Based on separate pilot data, a sample size of 24 children was calculated to detect an FRC difference of $5 \%$ between the different assessment times with an $\alpha$ error of .05 (corrected for multiple comparisons) and a $\beta$ error of 0.1 . 
Table 1. Diagnoses of children

\begin{tabular}{lc}
\hline Diagnosis & No. of Patients \\
\hline Tetralogy of Fallot & 9 \\
Ventricular septal defect & 6 \\
Mitral valve insufficiency & 4 \\
$\begin{array}{l}\text { Ventricular septal defect, aortic } \\
\text { valve insufficiency }\end{array}$ & 2 \\
Aortic valve insufficiency, mitral \\
$\quad$ valve insufficiency \\
$\begin{array}{l}\text { Mitral and tricuspid valve } \\
\quad \text { insufficiency }\end{array}$ \\
$\begin{array}{l}\text { Pulmonary valve agenesia } \\
\text { (absent valve) }\end{array}$ \\
$\begin{array}{l}\text { Total } \\
\text { Pala }\end{array}$ \\
$\quad$
\end{tabular}

Because the procedural data proved to be normally distributed, as analyzed by the Shapiro-Wilk test, data are reported as means (SD). To compare the data between the different assessment times, an analysis of variance for repeated measures was performed, and a Bonferoni test was used for post-hoc comparisons.

\section{Results}

All 24 children (mean [SD]: 4.8 [3.3] years; 15.3 [7.7] kg; 102 [27] cm; male/female ratio, 12:12) were successfully studied. Table 1 shows the indications for surgical correction. Figures 1 and 2 depict the individual and mean (SD) FRC and LCI changes at the different assessment times. Although FRC significantly improved after chest opening,

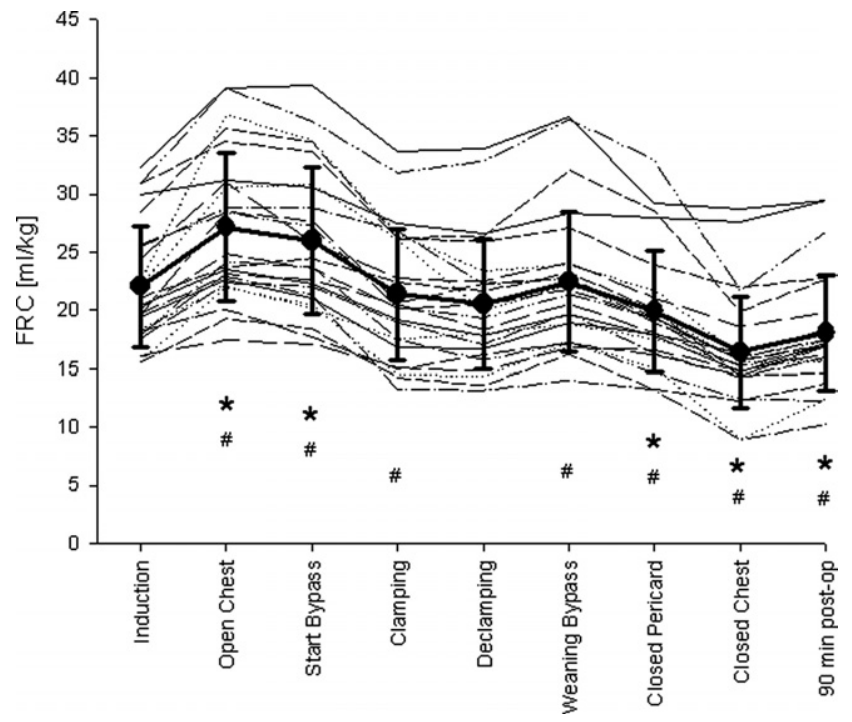

Figure 1. Functional residual capacity (FRC; in milliliters per kilogram) at the different assessment times. Data are presented as single values and as the mean (standard deviation). *Measurement is statistically significant toward baseline. "Measurement is statistically significant toward previous measurement, as determined by using analysis of variance for repeated measures.

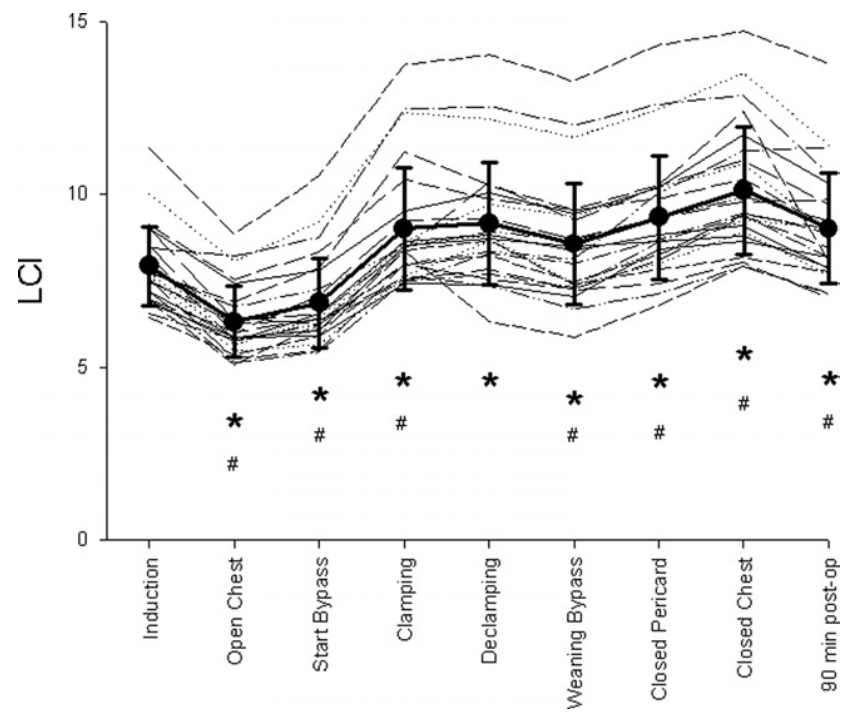

Figure 2. Lung clearance index (LCI) at the different assessment times. Data are presented as single values and as the mean (standard deviation). *Measurement is statistically significant toward baseline. \#Measurement is statistically significant toward previous measurement, as determined by using analysis of variance for repeated measures.

starting CPB and aortic clamping led to significant decreases in FRC (Table 2 and Figure 1). Reestablishment of pulmonary circulation was associated with a significant increase in FRC. However, this was followed by a significant decrease in FRC after removal of the retractor to close the pericardium, with a further decrease after chest closure. Ninety minutes after skin closure, the FRC improved slightly but remained significantly lower than the baseline value. LCI changes (Figure 2) were converse to those observed in FRC. Dead space volume did not change throughout the study period.

There was no evidence for the presence of aortopulmonary collaterals in children who underwent preoperative cardiac catheterization (children with tetralogy of Fallot). In addition, although we did not measure the venous return sucked by the vent during bypass, there was no overflow that might have led to changing the vent to a bigger size or increasing the speed of suction. Finally, we did not observe a flooding of the surgical field from the pulmonary artery itself, which further suggests the lack of a significant aortopulmonary collateral perfusion during CPB.

When separately calculating the changes in FRC in the small subgroups of children with cyanotic and acyanotic lesions, they reveal statistically significant differences only at the time point when CPB was initiated $(P=.009)$. 
Table 2. Mean (standard deviation) functional residual capacity and lung clearance index changes at the different assessment times

\begin{tabular}{|c|c|c|c|c|c|c|c|}
\hline \multirow[b]{2}{*}{ Assessment } & \multicolumn{4}{|c|}{ Functional residual capacity } & \multicolumn{3}{|c|}{ Lung clearance index } \\
\hline & Absolute (mL) & $\mathrm{mL} / \mathrm{kg}$ & $\begin{array}{l}\% \text { Change from } \\
\text { baseline }\end{array}$ & $\begin{array}{c}\% \text { Change from } \\
\text { previous } \\
\text { measurement }\end{array}$ & Absolute & $\begin{array}{l}\% \text { Change from } \\
\text { baseline }\end{array}$ & $\begin{array}{c}\% \text { Change from } \\
\text { previous } \\
\text { measurement }\end{array}$ \\
\hline After induction (baseline) & $351(222)$ & $22.1(5.2)$ & 0 & 0 & $7.92(1.2)$ & 0 & 0 \\
\hline $\begin{array}{l}\text { After sternotomy without } \\
\text { retractor }\end{array}$ & $383(234)$ & $24.1(5.3)$ & $9.7(8.3)$ & $9.7(8.3)$ & $7.19(1.3)$ & $-9.40(6.7)$ & $-9.40(6.7)$ \\
\hline Open chest with retractor & 435 (274) & $27.2(6.4)$ & $23.7(13.7)$ & $12.6(6.6)$ & $6.31(1.0)$ & $-20.2(7.8)$ & $-11.9(6.5)$ \\
\hline $\begin{array}{l}\text { Start of cardiopulmonary } \\
\text { bypass }\end{array}$ & $420(270)$ & $26.0(6.3)$ & $18.3(13.9)$ & $-4.35(4.4)$ & $6.85(1.3)$ & $-13.5(8.7)$ & 8.49 (6.4) \\
\hline Clamping of the aorta & $346(223)$ & $21.4(5.7)$ & $-3.1(12.3)$ & $-17.9(7.7)$ & $9.00(1.8)$ & $13.7(14.0)$ & $31.5(8.4)$ \\
\hline Declamping of the aorta & $334(226)$ & $20.5(5.6)$ & $-7.1(10.4)$ & $-3.64(7.4)$ & $9.16(1.8)$ & $15.4(12.5)$ & $2.05(8.8)$ \\
\hline $\begin{array}{l}\text { Weaning from cardiopulmonary } \\
\text { bypass }\end{array}$ & 365 (245) & $22.4(6.0)$ & 1.8 (11.6) & $9.70(5.6)$ & $8.56(1.8)$ & 7.70 (12.4) & $6.65(3.9)$ \\
\hline $\begin{array}{l}\text { Retractor removed, pericardium } \\
\text { closed }\end{array}$ & $320(206)$ & $19.9(5.2)$ & $-9.5(9.8)$ & $-11.0(5.0)$ & $9.33(1.8)$ & $17.4(10.8)$ & $9.35(5.3)$ \\
\hline Closed chest & $263(174)$ & $16.4(4.8)$ & $-25.8(11.1)$ & $-17.8(10.3)$ & $10.1(1.8)$ & $27.3(8.9)$ & $8.71(5.1)$ \\
\hline 30 min after the operation & 274 (178) & $17.1(4.7)$ & $-22.3(11.7)$ & $4.82(5.6)$ & $9.66(1.7)$ & $21.6(9.3)$ & $-4.38(4.7)$ \\
\hline 60 min after the operation & $280(184)$ & $17.5(4.8)$ & $-20.6(11.7)$ & $2.24(4.2)$ & $9.23(1.6)$ & $16.5(11.7)$ & $-4.03(7.0)$ \\
\hline 90 min after the operation & 288 (189) & $18.0(5.0)$ & $-18.0(11.9)$ & $3.36(3.7)$ & $9.01(1.6)$ & $13.7(9.8)$ & $-2.37(2.5)$ \\
\hline
\end{tabular}

\section{Discussion}

The results of the present study demonstrated that the FRC and LCI values in children undergoing cardiac surgery during CPB are not only influenced by the chest wall condition but are also highly dependent on pulmonary blood flow. Moreover, the decreases in FRC observed during a reduction in pulmonary blood flow are associated with increases in ventilation inhomogeneity (increased LCI values) and demonstrated the beneficial role of filled pulmonary capillary vessels in the maintenance of a stable alveolar architecture in a clinical setting. The involvement of this phenomenon is confirmed by the systematic increases in FRC and the decreases in LCI after reestablishment of pulmonary perfusion. Furthermore, the chest wall condition significantly affected the resting volume and the ventilation distribution.

\section{Methodologic Issues}

FRC and LCI measurements were obtained by using an $\mathrm{SF}_{6}$ multibreath washout technique that has been applied to intubated, mechanically ventilated children. ${ }^{17}$ The lung volumes and ventilation distribution values obtained in the present study agree with previously reported values in healthy preschool children matched for age and weight. ${ }^{17}$ These findings suggest that baseline resting static lung volumes in these children with congenital heart disease were not significantly impaired. In the present study, the positive end-expiratory pressure value of $3 \mathrm{~cm} \mathrm{H}_{2} \mathrm{O}$, tidal volume of $10 \mathrm{~mL} / \mathrm{kg}$, and $\mathrm{FIO}_{2}$ of 0.5 were kept constant during the measurements to maintain a comparable lung volume his- tory. After the end of the operation, the patients were kept in the operating theater for at least 90 minutes to ensure constant ventilatory and anesthetic conditions. This regimen minimized the potential bias of altered lung management on the last recordings of FRC and LCI. Further measurements were difficult to obtain because the patients were then transferred to the pediatric intensive care unit, and most of them were rapidly weaned from the ventilator and extubated within the following hours.

Ventilation homogeneity can be calculated by analyzing the washout curve of an insoluble tracer gas $\left(\mathrm{eg}, \mathrm{SF}_{6}\right)$ and described by various indices. ${ }^{18}$ Among them, LCI is a sensitive parameter of ventilation homogeneity with the advantage of being less affected by changes in tidal or dead space volume. ${ }^{18}$ In our study the tidal volume/FRC ratio changed with changes in FRC because the tidal volume was kept constant throughout the study period. This potentially could have affected the degree of ventilation inhomogeneity measured because the LCI is not completely independent of the tidal volume/FRC ratio. ${ }^{26}$ However, in spontaneously breathing healthy adults, LCI and mean dilution number are not sensitive enough to measure ventilation maldistribution that occurs with a change of posture or a change of the tidal volume/FRC ratio. ${ }^{27}$ This indicated that factors other than changes in the tidal volume/FRC ratio, such as partially collapsed alveoli and less well-distended distal bronchi, contribute to the observed ventilation maldistribution (eg, after chest closure). 


\section{Effect of Chest Wall Condition}

Opening of the chest by means of midsternotomy and positioning of a chest retractor, while maintaining the integrity of the pleural cavities, led to an increase in FRC of about $20 \%$. These values agree with results from previous studies determining the resting volume after sternotomy and retraction in children. ${ }^{28,29}$ Changing the transpulmonary pressure and the chest condition enhances the tendency of the lung parenchyma to expand, thus increasing the resting volume. Accordingly, chest opening led to a significant $(25 \%)$ decrease in LCI, confirming the improved ventilation homogeneity. These findings suggested that the chest condition accounted for approximately $20 \%$ of the changes in FRC and LCI observed at the beginning of cardiac surgery in children, with half of it being attributable to the midsternotomy and the other half to the retractor used. At the end of the operation, LCI changes had a converse effect to those seen at the beginning of the operation. Although the retractor removal during chest closure had a similar effect on FRC, like the insertion of the retractor in the beginning, the definitive closure of the thorax led to a greater decrease in FRC than the gain after midsternotomy, which might be partly attributed to the presence of chest drains, inflammation, and fluid extravasation in the lung. However, the changes in LCI might have been underestimated because the measurements can be influenced by the fact that the used $\mathrm{SF}_{6}$ multibreath washout technique detects only the volume and ventilation distribution of the gas in the pulmonary units, which communicate with the airway during the period of the measurement.

The decreases in FRC and ventilation homogeneity after chest closure agreed with those reported in adults and only slightly improved over the following 90 minutes, with the highest increase being noted in the first half hour. ${ }^{30}$ However, there was a greater tendency for smaller children to have larger changes in lung volumes at all assessment times. This phenomenon can be attributed to the highly compliant chest wall of the infant, which results in relatively low transpulmonary pressures at end expiration. This characteristic is responsible for an increased tendency for collapse of the small peripheral airways. ${ }^{17,31-34}$

\section{Effect of Pulmonary Circulation}

We found that running the $\mathrm{CPB}$ on a full regimen and clamping the aorta caused a large (18\%) decrease in FRC. Because the ventilator settings were identical before and after these recordings, this finding is attributed to the highly diminished pulmonary blood flow. Additionally, just starting $\mathrm{CPB}$ resulted in a significant decrease in FRC that might be related to the decrease in pulmonary circulatory flow. The observed loss in resting lung volume is the consequence of either airway narrowing or partial collapse of the functional alveolar units.
Lung hypoperfusion or complete absence of pulmonary perfusion has been shown to compromise the mechanical properties of the lungs. ${ }^{13,35-38}$ In line with our data, in an experimental setting lung volumes and pulmonary mechanics are highly dependent on pulmonary circulation; a decrease or an interruption of the pulmonary circulation results in a decrease in lung volumes and an increase in viscous resistance and elastance of the parenchyma, whereas the reestablishment of pulmonary perfusion leads to a recovery of lung volumes and mechanics. ${ }^{13}$ In the absence of capillary pressurization, the alveolar wall changes into a convoluted structure, whereas the presence of a capillary blood flow stabilizes the alveolar wall and reorganizes the elastin fibers with normalization of the alveolar geometry. ${ }^{13}$ In the present study it can therefore be assumed that after a reduction in pulmonary blood flow (after aortic clamping), the viscoelasticity of the alveoli decreased consecutively, leading to a loss in the stability of the alveolar geometry. These adverse changes in the lung periphery are then presumably reflected in the decreases in FRC and in the increases in LCI. In accordance with this mechanism, the reestablishment of the pulmonary circulation after weaning from CPB led to a significant increase in FRC and a decrease in LCI by restoring the stability of the alveolar wall after the appearance of the tethering effect exerted by the recommencement of pulmonary blood flow. In addition to this mechanism, the alveolar hypocapnia induced by the decreased pulmonary blood flow after $\mathrm{CPB}$ might have deteriorated the lung mechanics, ${ }^{39}$ contributing to a decreased FRC and increased LCI.

The present study is the first report of the changes in ventilation distribution before and after CPB in children. LCI increased significantly after the onset of CPB and aortic clamping, with a partial restoration once pulmonary circulation was reestablished. The loss in the tethering effect and the subsequent decrease in the resting volume were more readily seen in LCI alterations than in FRC changes. Accordingly, the loss in the alveolar stability was associated with a marked increase in the ventilation inhomogeneity (32\% increase in LCI after aortic clamping), suggesting that the diminished pulmonary circulation did not result in atelectasis but rather in a reduction of the available alveolar functional units. After reestablishment of the pulmonary circulation, ventilation homogeneity increased in parallel with the increase in FRC, further confirming the beneficial effect of pulmonary blood flow on alveolar wall stability and leading to alveolar recruitment.

\section{Conclusions}

The present study demonstrates the important role of both chest and alveolar wall configurations for maintaining an open lung and for determining lung resting volume and ventilation distribution. Although opening of the chest wall 
improved alveolar recruitment through changes in transpulmonary pressure, blood flow appeared essential for alveolar stability, presumably by exerting a tethering force caused by the filled capillaries on the alveolar walls.

We thank all the children and their families who participated in this study and J. Etlinger, BA, Department of Anesthesia, University of Basel, Switzerland, for editorial assistance.

\section{References}

1. Tonz M, Mihaljevic T, von Segesser LK, Fehr J, Schmid ER, Turina MI. Acute lung injury during cardiopulmonary bypass. Are the neutrophils responsible? Chest. 1995;108:1551-6.

2. Gilliland HE, Armstrong MA, McMurray TJ. The inflammatory response to pediatric cardiac surgery: correlation of granulocyte adhesion molecule expression with postoperative oxygenation. Anesth Analg. 1999;89:1188-91.

3. Vincent RN, Lang P, Elixson EM. Extravascular lung water in children immediately after operative closure of either isolated atrial septal defect or ventricular septal defect. Am J Cardiol. 1985;56:536-9.

4. Stayer SA, Diaz LK, East DL, Gouvion JN, Vencill TL, McKenzie $\mathrm{ED}$, et al. Changes in respiratory mechanics among infants undergoing heart surgery. Anesth Analg. 2004;98:49-55.

5. Habre W, Schutz N, Pellegrini M, Beghetti M, Sly PD, Hantos Z, et al. Preoperative pulmonary hemodynamics determines changes in airway and tissue mechanics following surgical repair of congenital heart diseases. Pediatr Pulmonol. 2004;38:470-6.

6. Verheij J, van Lingen A, Raijmakers PG, Spijkstra JJ, Girbes AR, Jansen EK, et al. Pulmonary abnormalities after cardiac surgery are better explained by atelectasis than by increased permeability oedema. Acta Anaesthesiol Scand. 2005;49:1302-10.

7. Reis Miranda D, Struijs A, Koetsier P, van Thiel R, Schepp R, Hop W, et al. Open lung ventilation improves functional residual capacity after extubation in cardiac surgery. Crit Care Med. 2005;33:2253-8.

8. Berry CB, Butler PJ, Myles PS. Lung management during cardiopulmonary bypass: is continuous positive airways pressure beneficial? Br J Anaesth. 1993;71:864-8.

9. Cogliati AA, Menichetti A, Tritapepe L, Conti G. Effects of three techniques of lung management on pulmonary function during cardiopulmonary bypass. Acta Anaesthesiol Belg. 1996;47:73-80.

10. Magnusson L, Zemgulis V, Tenling A, Wernlund J, Tyden H, Thelin $\mathrm{S}$, et al. Use of a vital capacity maneuver to prevent atelectasis after cardiopulmonary bypass: an experimental study. Anesthesiology. 1998;88:134-42.

11. Magnusson L, Zemgulis V, Wicky S, Tyden H, Thelin S, Hedenstierna G. Atelectasis is a major cause of hypoxemia and shunt after cardiopulmonary bypass: an experimental study. Anesthesiology. 1997;87: 1153-63.

12. Polese G, Lubli P, Mazzucco A, Luzzani A, Rossi A. Effects of open heart surgery on respiratory mechanics. Intensive Care Med. 1999;25: 1092-9.

13. Petak F, Babik B, Hantos Z, Morel DR, Pache JC, Biton C, et al. Impact of microvascular circulation on peripheral lung stability. Am J Physiol Lung Cell Mol Physiol. 2004;287:L879-89.

14. Tusman G, Bohm SH, Tempra A, Melkun F, Garcia E, Turchetto E, et al. Effects of recruitment maneuver on atelectasis in anesthetized children. Anesthesiology. 2003;98:14-22.

15. Tusman G, Bohm SH, Vazquez de Anda G, do Campo J, Lachmann B. "Alveolar recruitment strategy" improved arterial oxygenation during general anaesthesia. Br J Anaesth. 1999;82:8-13.

16. Schibler A, Hammer J, Isler R, Buess C, Newth CJ. Measurement of lung volume in mechanically ventilated monkeys with an ultrasonic flow meter and the nitrogen washout method. Intensive Care Med. 2004;30:127-32.

17. von Ungern-Sternberg BS, Hammer J, Schibler A, Frei FJ, Erb TO. Decrease of functional residual capacity and ventilation homogeneity following neuromuscular blockade in anesthetized young infants and preschool children. Anesthesiology. 2006;105:670-5.

18. Larsson A, Jonmarker C, Werner O. Ventilation inhomogeneity during controlled ventilation. Which index should be used? J Appl Physiol. 1988;65:2030-9.

19. East TD, Andriano KP, Pace NL. Automated measurement of functional residual capacity by sulfur hexafluoride washout. J Clin Monit. $1987 ; 3: 14-21$

20. Jonmarker C, Jansson L, Jonson B, Larsson A, Werner O. Measurement of functional residual capacity by sulfur hexafluoride washout. Anesthesiology. 1985;63:89-95.

21. Schibler A, Hall GL, Businger F, Reinmann B, Wildhaber JH, Cernelc $\mathrm{M}$, et al. Measurement of lung volume and ventilation distribution with an ultrasonic flow meter in healthy infants. Eur Respir J. 2002;20: 912-8.

22. Schibler A, Henning R. Positive end-expiratory pressure and ventilation inhomogeneity in mechanically ventilated children. Pediatr Crit Care Med. 2002;3:124-8.

23. Larsson A, Linnarsson D, Jonmarker C, Jonson B, Larsson H, Werner O. Measurement of lung volume by sulfur hexafluoride washout during spontaneous and controlled ventilation: further development of a method. Anesthesiology. 1987;67:543-50.

24. Gustafsson PM, Kallman S, Ljungberg H, Lindblad A. Method for assessment of volume of trapped gas in infants during multiple-breath inert gas washout. Pediatr Pulmonol. 2003;35:42-9.

25. Gustafsson PM, Aurora P, Lindblad A. Evaluation of ventilation maldistribution as an early indicator of lung disease in children with cystic fibrosis. Eur Respir J. 2003;22:972-9

26. Habib RH, Lutchen KR. Moment analysis of a multibreath nitrogen washout based on an alveolar gas dilution number. Am Rev Respir Dis. 1991;144:513-9.

27. Gronkvist M, Bergsten E, Gustafsson PM. Effects of body posture and tidal volume on inter- and intraregional ventilation distribution in healthy men. J Appl Physiol. 2002;92:634-42.

28. Jonmarker C, Larsson A, Werner O. Changes in lung volume and lung-thorax compliance during cardiac surgery in children 11 days to 4 years of age. Anesthesiology. 1986;65:259-65.

29. Dobbinson TL, Gray IG, Nisbet HI, Pelton DA, Levison H, Volgyesi G. Thoracic compliance and lung volumes in children with heart disease. Acta Anaesthesiol Scand. 1973;17:50-6.

30. Macnaughton PD, Braude S, Hunter DN, Denison DM, Evans TW. Changes in lung function and pulmonary capillary permeability after cardiopulmonary bypass. Crit Care Med. 1992;20:1289-94.

31. Stocks J. Respiratory physiology during early life. Monaldi Arch Chest Dis. 1999;54:358-64.

32. Bancalari E, Clausen J. Pathophysiology of changes in absolute lung volumes. Eur Respir J. 1998;12:248-58.

33. Lumb AB. Pregnancy, neonates and children. In: Nunn's applied respiratory physiology. 5th ed. Oxford: Butterworth-Heinemann; 2000. p. 319-33.

34. Papastamelos C, Panitch HB, England SE, Allen JL. Developmental changes in chest wall compliance in infancy and early childhood. J Appl Physiol. 1995;78:179-84.

35. Lubica H. Pathologic lung function in children and adolescents with congenital heart defects. Pediatr Cardiol. 1996;17:314-5.

36. Mitzner W, Lee W, Georgakopoulos D, Wagner E. Angiogenesis in the mouse lung. Am J Pathol. 2000;157:93-101.

37. Petak F, Habre W, Hantos Z, Sly PD, Morel DR. Effects of pulmonary vascular pressures and flow on airway and parenchymal mechanics in isolated rat lungs. J Appl Physiol. 2002;92:169-78.

38. Tremblay LN, Yamashiro T, DeCampos KN, Mestrinho BV, Slutsky AS, Todd TR, et al. Effect of hypotension preceding death on the function of lungs from donors with nonbeating hearts. J Heart Lung Transplant. 1996;15:260-8.

39. O'Cain CF, Hensley MJ, McFadden ERJ, Ingram RHJ. Pattern and mechanism of airway response to hypocapnia in normal subjects J Appl Physiol. 1979;47:8-12. 